\title{
Effect of specimen type on free immunoglobulin light chains analysis on the Roche Diagnostics cobas 8000 analyzer
}

\author{
Louis S. Nelson, Bryan Steussy, Cory S. Morris and Matthew D. Krasowski*
}

\begin{abstract}
The measurement of free immunoglobulin light chains is typically performed on serum; however, the use of alternative specimen types has potential benefits. Using the Freelite ${ }^{\mathrm{TM}}$ kappa and lambda free light chains assay on a Roche Diagnostics cobas 8000 c502 analyzer, we compared three specimen types (serum, EDTA-plasma and lithium heparin plasma separator gel-plasma) on 100 patients. Using Deming regression and eliminating outliers (limiting data to light chain concentrations below $400 \mathrm{mg} / \mathrm{L}$ ), the three specimen types showed comparable results for kappa light chain concentration, lambda light chain concentration, and kappa/lambda ratio with slopes close to 1.0 and y-intercepts close to zero. EDTA-plasma showed slightly more positive bias relative to serum than lithium heparin. Analysis using EDTA-plasma and lithium heparin plasma showed comparable linearity, precision, and temperature stability. A single sample showing hook effect (not in the comparison set) gave comparable results using either plasma specimen type. For the Freelite ${ }^{\mathrm{TM}}$ kappa and lambda free light chains assay, both EDTA-plasma or lithium heparin-plasma can serve as acceptable substitutes for serum, at least for the Roche cobas 8000 analyzer.
\end{abstract}

Keywords: Immunoglobulin light chains, Laboratory automation, Nephelometry, Plasma, Serum

\section{Background}

Measurement of kappa and lambda free immunoglobulin light chains in serum has been shown to be valuable in the diagnosis and management of a variety of diseases, especially plasma cell disorders such as multiple myeloma, Waldenström's macroglobulinemia, AL amyloidosis, and light chain deposition diseases (Bradwell et al. 2001; Dimopoulos et al. 2011; Dispenzieri et al. 2009, 2010; Hoedemakers et al. 2011; Katzmann et al. 2005; Lachmann et al. 2003; Morris et al. 2007; Snozek et al. 2008; Tosi et al. 2013). Serum free light chain analysis is often used in conjunction with serum and urine protein electrophoresis (Hoedemakers et al. 2011; Kim et al. 2014; McTaggart et al. 2013). Serum is the mandatory specimen for protein electrophoresis; thus, the same serum specimen is often used for measurement of free light chains. However, analysis of plasma may have

*Correspondence: matthew-krasowski@uiowa.edu

Department of Pathology, University of lowa Hospitals and Clinics, lowa City, IA 52242, USA potential practical advantages compared to serum. For example, the ability to use plasma as a specimen for free light chain analysis may limit number of blood collection tubes needed during phlebotomy for some patients (e.g., if plasma but not serum is needed for other tests coordered for a patient) or to allow add-on orders for free light chain analysis if serum is not available as a pre-existing specimen (Nelson et al. 2015). The ability to run free light chain analysis on automated chemistry instrumentation typically allows for faster turnaround time than protein electrophoresis, which requires more specialized instrumentation and result interpretation.

In this study we compared the differences between serum and plasma for measurement of kappa and lambda free light chains using the Freelite ${ }^{\mathrm{TM}}$ serum free light chain assays on a Roche Diagnostics cobas 8000 c502 analyzer. Plasma specimens obtained from ethylenediaminetetraacetic acid (EDTA)-anticoagulated tubes and lithium heparin plasma separator tubes (PST) were used for the comparisons. A previous study has compared plasma versus serum for another marketed free light chain assay

\section{Springer}


(N Latex FLC) and showed similar results using either specimen type (te Velthuis et al. 2011). Another study compared serum versus serum separator gel and lithium heparin plasma samples for the Freelite ${ }^{\mathrm{TM}}$ assay on a Dade Behring BNII analyzer (Hansen et al. 2012). However, there is no published study doing the same comparison for the Freelite ${ }^{\mathrm{TM}}$ assay on the Roche cobas system, and the manufacturer instructions for the Freelite ${ }^{\mathrm{TM}}$ assay on this analytical platform only list serum as the acceptable specimen type (Freelite ${ }^{\mathrm{TM}}$ Human Kappa Free and Human Lambda Free Light Chains package insert.).

\section{Experimental}

\section{Sample collection and processing for comparison studies}

This study had approval from the University of Iowa Institutional Review Board (protocol \#201407792). Testing was performed in the University of Iowa Hospitals and Clinics (UIHC) core clinical laboratory. The layout and informatics of this clinical laboratory has been detailed in previous publications (Krasowski et al. 2014, 2015). The inclusion criteria were: (1) patient who had free light chain analysis performed on a serum specimen, (2) EDTA-anticoagulated and lithium heparin PST specimens drawn on patient for clinical testing during same phlebotomy encounter, and (3) sufficient specimen remaining in the EDTA and PST specimens for light chain analysis after performance of provider-ordered clinical testing. The details on the three specimen types were: BD Vacutainer ${ }^{\circledR}$ red top silica clot activator coated tube (BD Diagnostics, Franklin Lakes, NJ), BD Vacutainer $^{\circledR}$ light green top plasma separator tubes $\left(\mathrm{PST}^{\mathrm{TM}}\right.$ ) containing polymer gel and lithium heparin (BD Diagnostics), and BD Vacutainer ${ }^{\circledR}$ pink top spray coated $\mathrm{K}_{2}$ EDTA tube (BD Diagnostics). No extra tubes were drawn on any patient for purposes of this study, i.e., all analyses used pre-existing specimens leftover from clinical testing that would otherwise have been discarded.

Upon completion of the clinically ordered tests, the specimens were transferred to a refrigerator for storage using a Roche Diagnostics (Indianapolis, IN) P701 automated archival retrieval system (Nelson et al. 2015). Samples were stored for up to $16 \mathrm{~h}$ until they were retrieved for use in the study. When samples were retrieved, they were centrifuged and loaded on to the Roche Diagnostics cobas 8000 Modular Analytics System c502 analyzer and assayed using the Freelite ${ }^{\mathrm{TM}}$ kappa and lambda free light chains assay (Freelite ${ }^{\mathrm{TM}}$ Human Kappa Free and Human Lambda free light chains package insert 2001).

Following the package insert procedure, kappa light chain measurements for serum specimens are linear to $56.25 \mathrm{mg} / \mathrm{L}$. Values that exceed $56.25 \mathrm{mg} / \mathrm{L}$ are treated with $\times 10$ dilution with saline. Values that still exceed linearity require a manual $\times 21$ dilution with saline. Lambda light chain measurements are linear to $93.33 \mathrm{mg} / \mathrm{L}$. Similar to the procedure with kappa light chains, lambda light chain values that exceed $93.33 \mathrm{mg} / \mathrm{L}$ are treated with $\times 10$ dilution with saline. Values that still exceed linearity require a manual $\times 21$ dilution with saline.

\section{Linearity studies}

Linearity was determined according to CLSI guideline EP6A (Clinical and Laboratory Standards Institute 2003) using plasma samples just above the upper measuring range for serum, i.e., $56.25 \mathrm{mg} / \mathrm{L}$ for kappa and $93.33 \mathrm{mg} / \mathrm{L}$ for lambda. At least 10 dilutions of $90-2.5 \%$ were measured for both EDTA-plasma and lithium heparin PST matrices. Five replicates for each dilution were measured. The mean result was analyzed by linear and cubic analysis. Fits were evaluated using the Microsoft Excel add-in Analyze-it ${ }^{\circledR}$.

\section{Method imprecision}

The precision study was performed according to CLSI EP5-A2 guideline (Clinical and Laboratory Standards Institute 2004). Plasma pools were made from routine patient samples that had no detectable monoclonal bands with serum electrophoresis and immunotyping.

\section{Reference ranges and medical decision levels}

The normal (reference) ranges for the free light chains following manufacturer recommendations in the package insert are: kappa (3.30-19.40 mg/L), lambda (5.71$26.30 \mathrm{mg} / \mathrm{L}), \mathrm{kappa} / \mathrm{lambda}$ ratio $(0.26-1.65)$. The lower and upper limits of the reference ranges for serum in the assay package insert were considered the medical decision levels (MDL). Assay measurement using serum (specimen type recommended in package insert) was considered the gold standard.

\section{Statistical analysis}

Linear regression and statistical analysis was performed using EP Evaluator release 11 (Data Innovations, Inc., South Burlington, VT). Deming linear regression was performed. Identification of outliers used an algorithm in EP Evaluator that identifies points whose distance from the regression line exceeds 10 times the standard error of estimate (SEE), where SEE is computed from the data set with outliers excluded.

\section{Results}

\section{Precision studies}

The precision of the kappa and lambda light chain assays at different levels of control material are summarized in 
Table 1 . The coefficient of variation $(\mathrm{CV})$ was less than $5 \%$ for the within- and between-run precision studies. The results of the precision studies for plasma pools are summarized in Fig. 1. The \% CV was generally 5-7 \% or less across most of the measuring range except for kappa and lambda concentrations less than $5 \mathrm{mg} / \mathrm{L}$. At concentrations near $1 \mathrm{mg} / \mathrm{L}$, the \% CV values approach $20 \%$.

\section{Linearity studies}

Serial dilutions of samples with a concentration just above the measuring range $(56.25 \mathrm{mg} / \mathrm{L}$ for kappa and $93.33 \mathrm{mg} / \mathrm{L}$ for lambda) were prepared. For kappa, linearity was confirmed between 1.0 and $56.25 \mathrm{mg} / \mathrm{L}$ for both EDTA-plasma and lithium heparin PST (maximum difference between linear and cubic fit of $18.8 \%$ ). For lambda, linearity was confirmed between 0.8 and $93.33 \mathrm{mg} / \mathrm{L}$ (maximum difference between linear and cubic fit of $17.4 \%)$.

Table 1 Precision using two different levels of control material

\begin{tabular}{llll}
\hline $\begin{array}{l}\text { Light chain } \\
\text { assay }\end{array}$ & Mean (mg/L) & $\begin{array}{l}\text { Within-run } \\
\text { imprecision } \% \\
\text { CV }(\mathbf{n}=\mathbf{1 0})\end{array}$ & $\begin{array}{l}\text { Between-run } \\
\text { imprecision \% } \\
\text { CV }(\mathbf{n}=\mathbf{2 0})\end{array}$ \\
\hline Kappa & 17.4 & 2.9 & 4.8 \\
Kappa & 34.1 & 3.5 & 4.6 \\
Lambda & 30.0 & 3.4 & 4.9 \\
Lamdba & 63.3 & 2.6 & 4.5
\end{tabular}

CV coefficient of variation

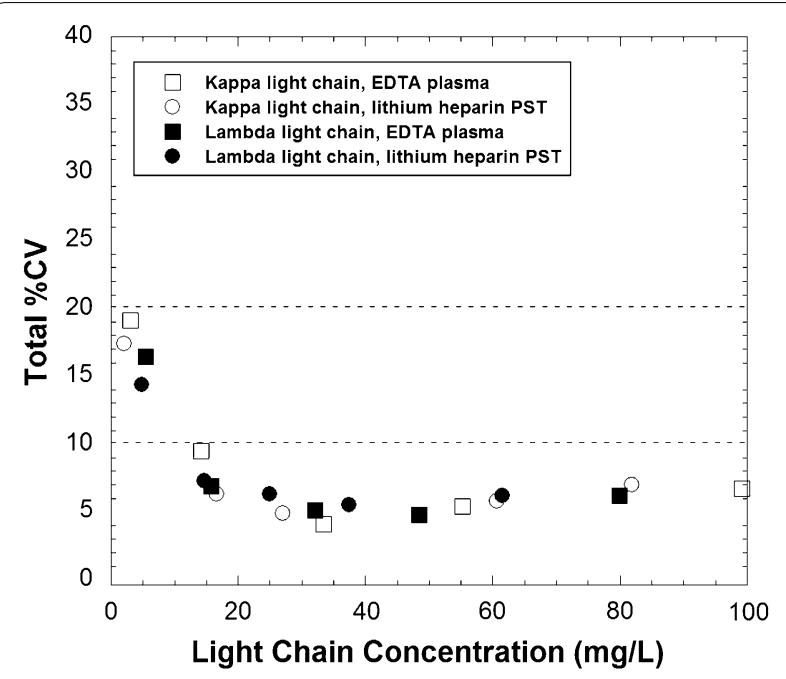

Fig. 1 Precision profile of the total coefficient of variation (CV) estimated according to CLSI EP5-A2. Squares (open and filled) indicate kappa and lambda concentrations, respectively, using EDTA-plasma. Circles (open and filled) indicate kappa and lambda concentrations, respectively, using lithium heparin plasma separator tubes

\section{Method comparison}

Samples from a total of 100 patients met the inclusion criteria for this study with sufficient serum, EDTA-plasma, and lithium heparin-plasma for free light chain analysis. Scatterplots for kappa, lambda and kappa/lambda ratio are shown for all 100 samples in Fig. 2 and for the subset of kappa and lambda values less than $400 \mathrm{mg} / \mathrm{L}$ in Fig. 3. By classifying the specimens on the basis of the reference intervals, there was 84 and $86 \%$ agreement, respectively, between serum and either EDTA-plasma or lithium heparin PST specimens for the kappa light chain assay (Table 2). The agreement rate was $95 \%$ for the lambda light chain assays (serum versus either EDTA-plasma and lithium heparin plasma) and $98 \%$ for the kappa/lambda ratio (serum versus either EDTA-plasma and lithium heparin plasma) (Table 2). All of the discrepancies with respect to reference interval were the result of the plasma result being higher than the value obtained from serum (Table 2). A summary of the specimens showing discrepancies is in Table 3, with clinical history and age/gender of patient described.

Comparison between serum and the two plasma specimen types was done by Deming linear regression. Outliers identified in the analysis were predominantly due to specimens with kappa and lambda concentrations exceeding $400 \mathrm{mg} / \mathrm{L}$ (thus Fig. 3 is restricted to kappa and lambda concentrations less than $400 \mathrm{mg} / \mathrm{L}$ ). The outliers are summarized in Table 4 (some of these overlapped with the specimens described in Table 3).

Linear regression parameters are summarized in Table 5. For all comparisons, slopes are close to 1.0. A slightly more noticeable positive bias was noted with EDTA-plasma versus serum. For lithium heparin PST versus serum, the confidence intervals for the slope and $y$-intercept for kappa light chain, lambda light chain, and kappa/lambda ratio overlapped with 1.000 and 0.0 , respectively. At the MDL, the confidence intervals overlapped with that for serum.

\section{Stability studies}

Stability studies were performed for pooled plasma samples stored either refrigerated $\left(4{ }^{\circ} \mathrm{C}\right)$ or frozen at $-20{ }^{\circ} \mathrm{C}$. Results were generally within $10 \%$ of those obtained at initial measurement (Fig. 4). The highest variability was seen at kappa and lambda concentrations less than $10 \mathrm{mg} / \mathrm{L}$, similar to that described above for the precision studies (Fig. 1).

\section{Antigen excess}

During the time period of study, a single specimen was analyzed that showed marked hook effect for lambda light chain. This specimen was from a patient whose specimens had previously shown hook effect during 

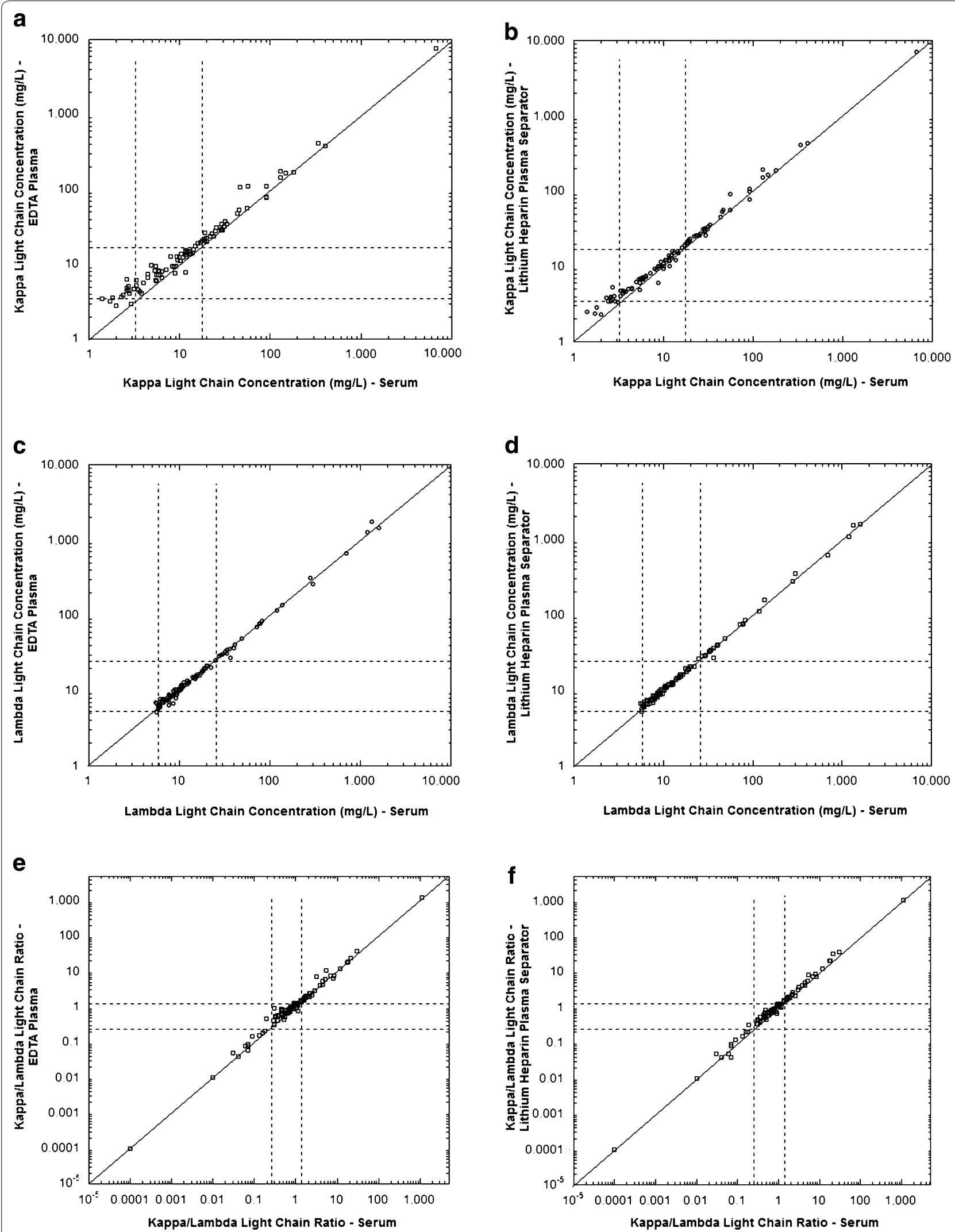

Fig. 2 Comparisons of serum versus EDTA-plasma or lithium heparin-plasma separator tube as specimens for measurement of free light chains $(n=100)$. The graphs are scatter plots of data for kappa concentration $(\mathbf{a}, \mathbf{b})$, lambda concentration $(\mathbf{c}, \mathbf{d})$, and kappa/lambda ratio $(\mathbf{e}, \mathbf{f})$. The line is the line of identity 

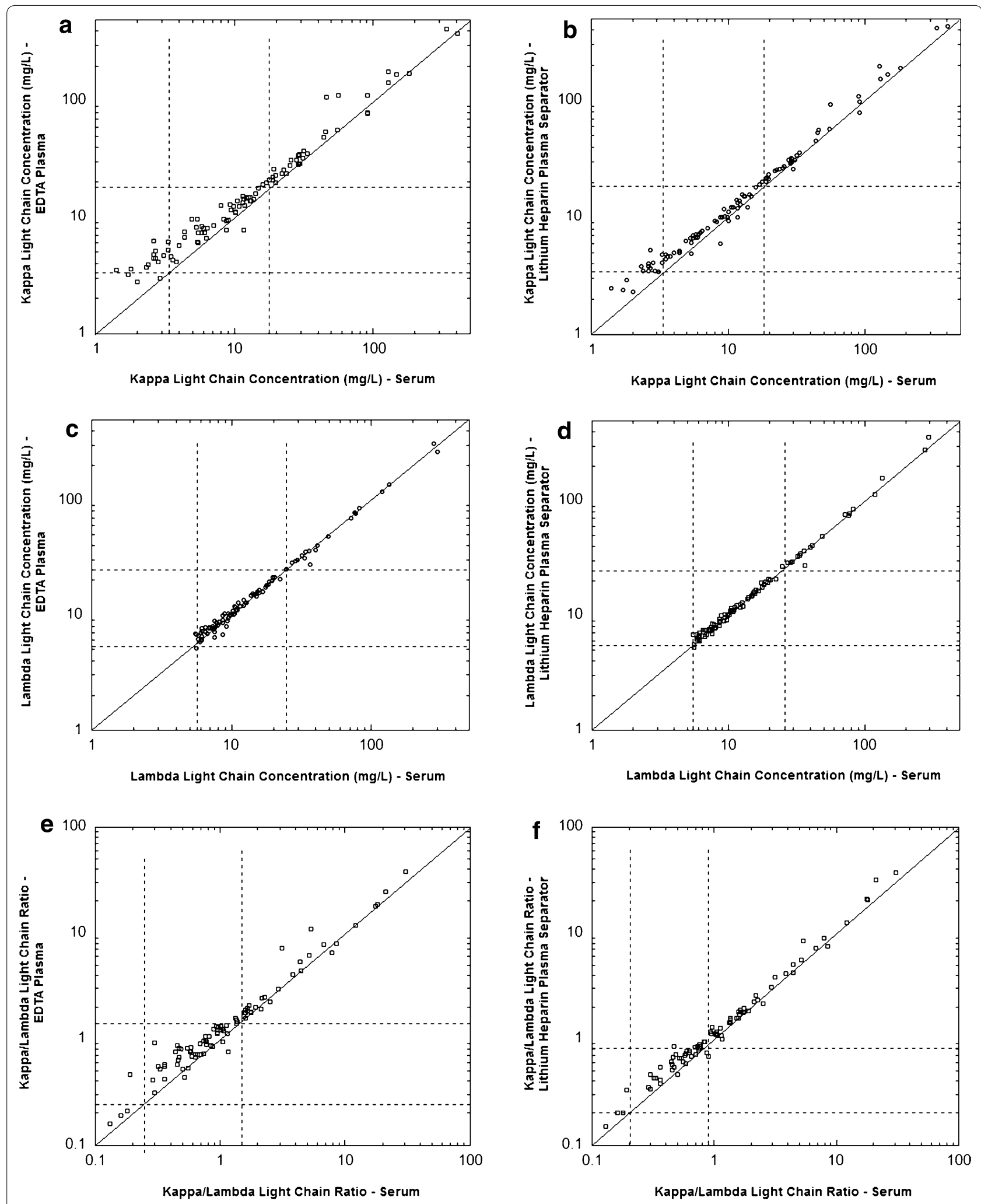

Fig. 3 Comparisons of serum versus EDTA-plasma or lithium heparin-plasma separator tube as specimens for measurement of free light chains showing subset of data. The graphs are scatter plots of data for kappa concentration (a, b; restricted to $400 \mathrm{mg} / \mathrm{L}$ or less), lambda concentration (c, d; restricted to $400 \mathrm{mg} / \mathrm{L}$ or less), and kappa/lambda ratio (e, $\mathbf{f}$; restricted to 100 or less). The line is the line of identity 
Table 2 Concordance tables between plasma and serum for light chain analysis

\begin{tabular}{|c|c|c|c|c|}
\hline Assay & Comparison & Identical \% & $\begin{array}{l}\text { Serum below ref. range/plasma } \\
\text { within ref. range }\end{array}$ & $\begin{array}{l}\text { Serum within ref. range/ } \\
\text { plasma above ref. range }\end{array}$ \\
\hline Kappa & EDTA vs. serum & 84 & 11 & 5 \\
\hline Kappa & Lithium heparin PST vs. serum & 86 & 10 & 4 \\
\hline Lambda & EDTA vs. serum & 98 & 2 & 0 \\
\hline Lambda & Lithium heparin PST vs. serum & 98 & 1 & 1 \\
\hline Kappa/lambda ratio & EDTA vs. serum & 95 & 1 & 4 \\
\hline Kappa/lambda ratio & Lithium heparin PST vs. serum & 95 & 1 & 4 \\
\hline
\end{tabular}

Table 3 Samples with discrepancy with respect to reference intervals

\begin{tabular}{|c|c|c|c|c|c|c|c|c|c|}
\hline \multirow[t]{2}{*}{ Patient age, gender, and clinical history } & \multicolumn{3}{|l|}{ Serum } & \multicolumn{3}{|c|}{ EDTA-plasma } & \multicolumn{3}{|c|}{ Lithium heparin PST } \\
\hline & $\begin{array}{l}\text { Kappa } \\
\text { (mg/L) }\end{array}$ & $\begin{array}{l}\text { Lambda } \\
\text { (mg/L) }\end{array}$ & $K / L$ & $\begin{array}{l}\text { Kappa } \\
\text { (mg/L) }\end{array}$ & $\begin{array}{l}\text { Lambda } \\
\text { (mg/L) }\end{array}$ & $\mathrm{K} / \mathrm{L}$ & $\begin{array}{l}\text { Kappa } \\
\text { (mg/L) }\end{array}$ & $\begin{array}{l}\text { Lambda } \\
\text { (mg/L) }\end{array}$ & $\mathrm{K} / \mathrm{L}$ \\
\hline \multicolumn{10}{|l|}{ Discrepancy involving kappa } \\
\hline 60 Y M, multiple myeloma, IgG kappa & 2.6 & 5.9 & 0.44 & 4.4 & 5.8 & 0.76 & 3.8 & 6.2 & 0.61 \\
\hline 66 Y F, multiple myeloma, lgG lambda & 2.7 & 5.8 & 0.47 & 4.4 & 6.6 & 0.67 & 3.7 & 6.8 & 0.54 \\
\hline 44 Y F, multiple myeloma, IgG lambda & 17.8 & 40.0 & 0.45 & 20.8 & 36.8 & 0.57 & 20.2 & 39.5 & 0.51 \\
\hline 60 Y F, multiple myeloma, lgG lambda & 18.8 & 10.7 & 1.76 & 20.8 & 11.6 & 1.79 & 20.1 & 11.1 & 1.81 \\
\hline 61 Y M, multiple myeloma, lgG kappa & 2.8 & 6.1 & 0.46 & 4.1 & 6.5 & 0.63 & 4.1 & 6.1 & 0.67 \\
\hline 51 Y M, multiple myeloma, IgG kappa & 2.7 & 5.8 & 0.47 & 5.1 & 6.2 & 0.82 & 5.3 & 6.2 & 0.85 \\
\hline 86 Y F, multiple myeloma, lambda light chain & 2.3 & 76 & 0.03 & 3.7 & 77.5 & 0.05 & 3.8 & 75.1 & 0.05 \\
\hline 60 Y F, multiple myeloma, IgA lambda & 2.4 & 6.7 & 0.36 & 3.9 & 6.9 & 0.57 & 3.5 & 6.5 & 0.54 \\
\hline 70 Y F, multiple myeloma, IgA lambda & 2.6 & 8.1 & 0.32 & 4.8 & 8.7 & 0.55 & 3.5 & 8.2 & 0.43 \\
\hline 39 Y M, multiple myeloma, lgG lambda & 2.6 & 8.6 & 0.30 & 6.3 & 6.8 & 0.93 & 4 & 8.7 & 0.46 \\
\hline 60 Y M, hairy cell leukemia & 19.1 & 18.7 & 1.02 & 26.1 & 19.6 & 1.33 & 21.8 & 19.7 & 1.11 \\
\hline 62 Y M, biclonal lgG kappa + lambda light chain ${ }^{a}$ & 3.1 & 1195 & $<0.01$ & 4.7 & 1275 & $<0.01$ & 3.4 & 1103 & $<0.01$ \\
\hline 66 Y F, multiple myeloma, lambda light chain ${ }^{a}$ & 17.0 & 296 & 0.06 & 19.7 & 263 & 0.08 & 19.3 & 359 & 0.05 \\
\hline \multicolumn{10}{|l|}{ Discrepancy involving kappa and lambda } \\
\hline 53 Y F, multiple myeloma, lgG kappa & 18.9 & 24.7 & 0.77 & 21.9 & 25.0 & 0.88 & 21.9 & 26.6 & 0.82 \\
\hline 84 Y M, multiple myeloma, lamba light chain & 2.9 & 5.6 & 0.52 & 3.0 & 6.8 & 0.44 & 3.5 & 5.3 & 0.66 \\
\hline 51 Y M, multiple myeloma, IgG kappa & 1.8 & 5.5 & 0.33 & 3.6 & 6.9 & 0.52 & 2.9 & 6.8 & 0.43 \\
\hline \multicolumn{10}{|l|}{ Discrepancy involving kappa and kappa/lambda ratio } \\
\hline 54 Y F, multiple myeloma, kappa light chain & 1.4 & 7.2 & 0.19 & 3.5 & 7.6 & 0.46 & 2.5 & 7.6 & 0.33 \\
\hline \multicolumn{10}{|l|}{ Discrepancy involving kappa/lambda ratio } \\
\hline 67 Y M, multiple myeloma, IgG kappa & 29.1 & 18.3 & 1.59 & 34.4 & 18.4 & 1.87 & 29.3 & 18.5 & 1.58 \\
\hline 64 Y M, multiple myeloma, kappa light chain & 21.9 & 13.8 & 1.59 & 23.7 & 14.9 & 1.59 & 25.1 & 13.9 & 1.81 \\
\hline 57 Y F, multiple myeloma, lgG lambda & 25.1 & 15.7 & 1.60 & 27.7 & 15.6 & 1.78 & 26.2 & 15.5 & 1.69 \\
\hline 55 Y M, multiple myeloma, lambda light chain & 12.1 & 7.4 & 1.64 & 14.8 & 7.5 & 1.97 & 13.9 & 7.4 & 1.88 \\
\hline 59 Y M, Waldenstroms, IgM lambda & 19.8 & 12.6 & 1.57 & 22.7 & 12.7 & 1.79 & 23.5 & 12.9 & 1.82 \\
\hline
\end{tabular}

PST plasma separator tube

a Also identified as outlier for lambda light chain analysis by Deming regression (Table 4)

multiple occasions. Specimens from this patient were not in the comparison studies (occurred after those studies completed). The hook effect was comparable in EDTAplasma and lithium heparin PST specimen. In particular, the apparent lambda light chain concentration in undiluted specimens was 89.3 and $89.8 \mathrm{mg} / \mathrm{L}$, respectively, for EDTA-plasma and lithium heparin PST specimens. Dilution analysis shown the actual lambda concentrations to be 4053 and $3862 \mathrm{mg} / \mathrm{L}$, respectively, in these two sample types. 
Table 4 Outliers identified by Deming regression analysis

\begin{tabular}{|c|c|c|c|c|c|c|c|c|c|}
\hline \multirow[t]{2}{*}{ Patient age, gender, and clinical history } & \multicolumn{3}{|l|}{ Serum } & \multicolumn{3}{|c|}{ EDTA-plasma } & \multicolumn{3}{|c|}{ Lithium heparin PST } \\
\hline & $\begin{array}{l}\text { Kappa } \\
\text { (mg/L) }\end{array}$ & $\begin{array}{l}\text { Lambda } \\
\text { (mg/L) }\end{array}$ & $K / L$ & $\begin{array}{l}\text { Kappa } \\
\text { (mg/L) }\end{array}$ & $\begin{array}{l}\text { Lambda } \\
\text { (mg/L) }\end{array}$ & K/L & $\begin{array}{l}\text { Kappa } \\
\text { (mg/L) }\end{array}$ & $\begin{array}{l}\text { Lambda } \\
\text { (mg/L) }\end{array}$ & $\mathrm{K} / \mathrm{L}$ \\
\hline \multicolumn{10}{|l|}{ Kappa outliers } \\
\hline 60 Y M, multiple myeloma, kappa light chain & 46.1 & 14.7 & 3.14 & 107 & 15.0 & 7.16 & 55.8 & 14.7 & 3.80 \\
\hline 59 Y F, multiple myeloma, IgG kappa & 6684 & 6.1 & 1096 & 7764 & 6.1 & 1273 & 7125 & 6.7 & 1063 \\
\hline 52 Y M, multiple myeloma, lgG kappa & 337 & 11.0 & 30.6 & 419 & 11.1 & 37.8 & 415 & 11.2 & 37.1 \\
\hline 60 Y M, multiple myeloma, lgG kappa & 56.2 & 10.5 & 5.35 & 112 & 10.3 & 10.87 & 91.9 & 10.8 & 8.51 \\
\hline 59 Y M, multiple myeloma, lgG kappa & 128 & 6.1 & 21.03 & 177 & 7.2 & 24.6 & 197 & 6.2 & 31.8 \\
\hline \multicolumn{10}{|l|}{ Lambda outliers } \\
\hline 60 Y M, plasma cell leukemia, IgG lambda & 4.0 & 693 & 0.01 & 5.7 & 672 & 0.01 & 5.0 & 621 & 0.01 \\
\hline 74 Y F, multiple myeloma, lgG lambda & 4.4 & 1590 & 0.00 & 6.7 & 1457 & 0.00 & 5.2 & 1571 & 0.00 \\
\hline 55 Y F, multiple myeloma, lambda light chain & 11.8 & 1334 & 0.01 & 12.7 & 1747 & 0.01 & 12.0 & 1562 & 0.01 \\
\hline 65 Y M, multiple myeloma, lambda light chain & 9.9 & 278 & 0.04 & 12.5 & 311 & 0.04 & 10.1 & 278 & 0.04 \\
\hline 59 Y F, acute renal failure, seropositive rheumatoid arthritis & 29.8 & 36.4 & 0.82 & 28.8 & 27.2 & 1.06 & 25.9 & 27.4 & 0.95 \\
\hline 62 Y M, biclonal lgG kappa + lambda light chain & 3.1 & 1195 & $<0.01$ & 4.7 & 1275 & $<0.01$ & 3.4 & 1103 & $<0.01$ \\
\hline 66 Y F, multiple myeloma, lambda light chain & 17.0 & 296 & 0.06 & 19.7 & 263 & 0.08 & 19.3 & 359 & 0.05 \\
\hline
\end{tabular}

PST plasma separator tube

Table 5 Linear regression summary statistics of specimen comparisons ${ }^{\mathrm{a}}$

\begin{tabular}{|c|c|c|c|c|c|}
\hline & Slope $(95 \% \mathrm{Cl})^{\mathbf{b}}$ & Y-intercept $(95 \% \mathrm{Cl})^{\mathrm{b}}(\mathrm{mg} / \mathrm{L})$ & $\begin{array}{l}\text { Correlation coef- } \\
\text { ficient }\end{array}$ & $\begin{array}{l}95 \% \mathrm{Cl} \text { at lower } \mathrm{MDL}^{\mathrm{c}} \\
(\mathrm{mg} / \mathrm{L})\end{array}$ & $\begin{array}{l}95 \% \mathrm{Cl} \text { at upper } \\
\mathrm{MDL}^{\mathrm{C}}(\mathrm{mg} / \mathrm{L})\end{array}$ \\
\hline \multicolumn{6}{|c|}{ EDTA vs. serum } \\
\hline Kappa & $0.969(0.950-0.988)$ & $2.58(1.54-3.64)$ & 0.9954 & $4.8-6.8$ & $20.4-22.4$ \\
\hline Lambda & $0.995(0.986-1.003)$ & $0.367(0.127-0.608)$ & 0.9992 & $5.8-6.3$ & $26.3-26.7$ \\
\hline $\mathrm{k} / \lambda$ ratio & $1.001(0.982-1.021)$ & $0.133(0.066-0.199)$ & 0.9957 & $0.33-0.46$ & $1.73-1.84$ \\
\hline \multicolumn{6}{|c|}{ Li-heparin plasma separator tube vs. serum } \\
\hline Kappa & $1.081(1.063-1.100)$ & $0.64(-0.38$ to 1.67$)$ & 0.9964 & $3.2-5.2$ & $19.4-22.5$ \\
\hline Lambda & $0.988(0.981-1.000)$ & $0.279(-0.101$ to 0.557$)$ & 1.0000 & $5.7-6.3$ & $26.1-26.6$ \\
\hline $\mathrm{k} / \lambda$ ratio & $1.175(1.154-1.196)$ & -0.091 ( -0.188 to 0.007$)$ & 0.9961 & $0.12-0.31$ & $1.65-1.83$ \\
\hline
\end{tabular}

a Analysis uses Deming regression excluding outliers (see Table 4)

b $\mathrm{Cl}$ confidence interval

c MDL medical decision limit: kappa, 3.3 and $19.4 \mathrm{mg} / \mathrm{L}$; lambda, 5.7 and $26.3 \mathrm{mg} / \mathrm{L} ; \mathrm{K} / \mathrm{\lambda}$ ratio, 0.26 and 1.65

\section{Discussion}

Overall, EDTA-plasma and lithium heparin-plasma gave comparable results to serum for kappa light chain concentration, lambda light chain concentration, and kappa/ lambda ratio for the Freelite ${ }^{\mathrm{TM}}$ assays performed on the cobas 8000 c502 analyzer. Similar to previous reports (Hansen et al. 2012; te Velthuis et al. 2011), these data suggest that plasma is an acceptable specimen for free light chain analysis. The precision, linearity, and analyte stability in plasma is also comparable to that described for serum in previous publications (Altinier et al. 2013; Briand et al. 2010; Cha et al. 2014; Hansen et al. 2012; Pretorius et al. 2012; Tate et al. 2003, 2009; Vercammen et al. 2015).
The highest variability seen in our study was with very low or very high kappa and lambda concentrations. This was evident in the regression outlier analysis. The light chain analysis procedure in the package insert for the Freelite $^{\mathrm{TM}}$ assay on the cobas 8000 analyzers requires two dilutions (one on-line and one manual) for the highest concentrations (kappa greater than $563 \mathrm{mg} / \mathrm{L}$ and lambda greater than $933 \mathrm{mg} / \mathrm{L}$ ). These dilutions offer potential for error. At high concentrations of free light chains, antigen excess is also possible (Bosmann et al. 2010; Vercammen et al. 2015). We did not study antigen excess in detail but did observe comparable results with both plasma specimen types in a patient previously observed to have hook effect with lambda concentrations. Specimens with very 


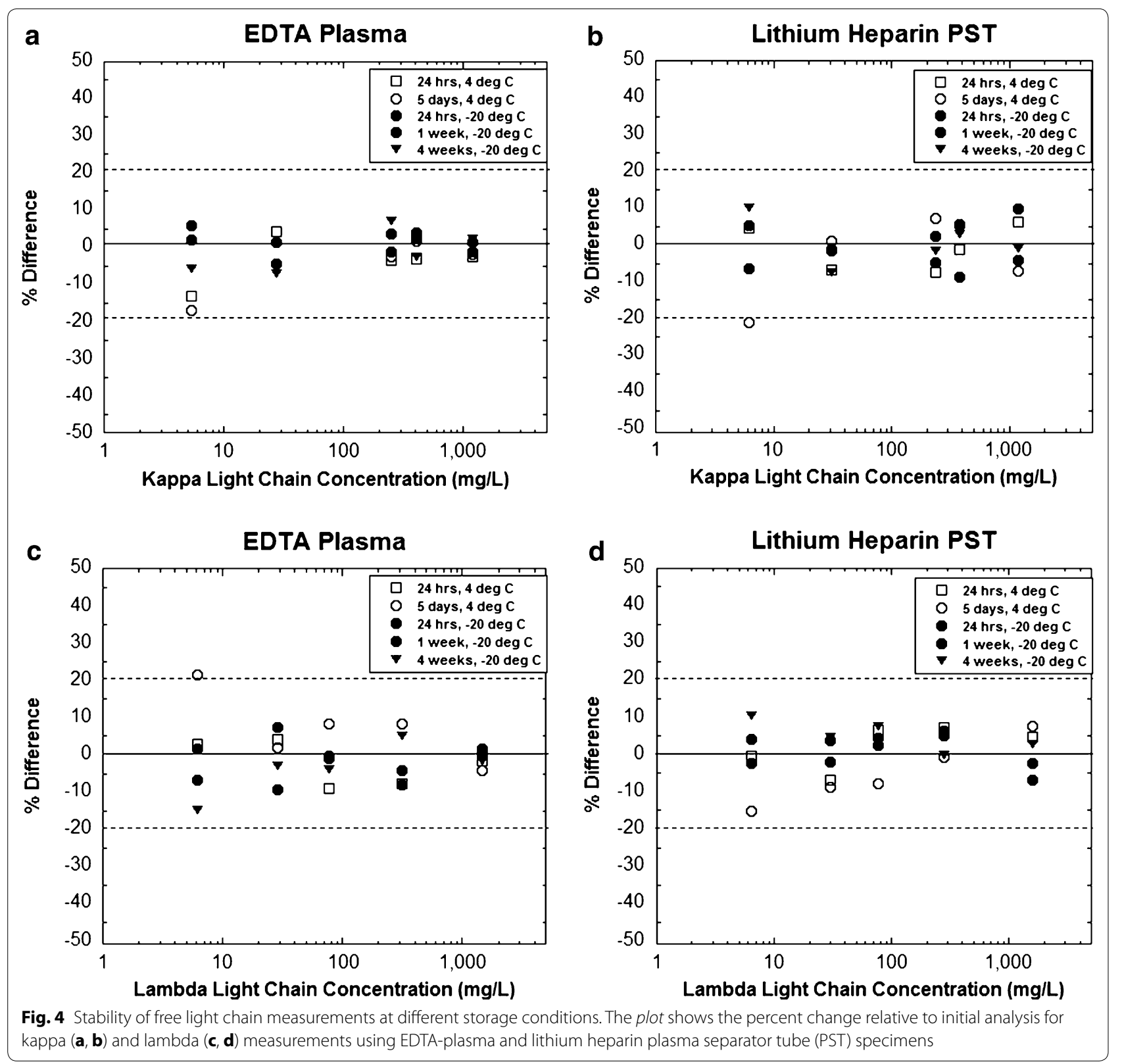

low values of kappa or lambda can also lead to higher variability in the kappa/lambda ratio, especially with the high imprecision typical of analyses in these low concentration ranges (Altinier et al. 2013; Briand et al. 2010; Cha et al. 2014; Hansen et al. 2012; Pretorius et al. 2012; Tate et al. 2003, 2009; Vercammen et al. 2015).

While plasma gave comparable results to serum in our study, it is probably prudent to use a single specimen type and analyzer platform for patient analysis. Reference intervals and medical decision levels should be reassessed carefully for any specimen type other than serum.
The trending of light chain values is used for treatment decisions and consistency in analysis is important. Future studies can focus on different instrument platforms and assay formats. A larger set of samples can also facilitate detailed studies on how plasma compares with serum with respect to antigen excess.

\section{Author's contributions}

LSN and CSM performed the data collection. LSN and BS performed data analysis and drafted the manuscript. MDK was involved in the study design, interpretation, and data analysis and also completed the final draft of the manuscript. All authors read and approved the final manuscript. 


\section{Acknowledgements}

MDK thanks the Department of Pathology (Dr. Nitin Karandikar, Department Executive Officer) for providing research funding. The authors thank Priyal Patel for assistance with the study of the sample showing hook effect.

\section{Competing interests}

The authors declare that they have no competing interests.

Received: 24 June 2015 Accepted: 18 November 2015

Published online: 08 December 2015

\section{References}

Altinier S, Seguso M, Zaninotto M, Varagnolo M, Adami F, Angeli P, Plebani M (2013) Serum free light chain reference values: a critical approach. Clin Biochem 46:691-693. doi:10.1016/j.clinbiochem.2013.01.014 (S00099120(13)00041-6 [pii])

Bosmann M, Kossler J, Stolz H, Walter U, Knop S, Steigerwald U (2010) Detection of serum free light chains: the problem with antigen excess. Clin Chem Lab Med 48:1419-1422. doi:10.1515/CCLM.2010.283

Bradwell AR, Carr-Smith HD, Mead GP, Tang LX, Showell PJ, Drayson MT, Drew R (2001) Highly sensitive, automated immunoassay for immunoglobulin free light chains in serum and urine. Clin Chem 47:673-680

Briand PY, Decaux O, Caillon H, Grosbois B, Le Treut A, Guenet L (2010) Analytical performance of the serum free light chain assay. Clin Chem Lab Med 48:73-79. doi:10.1515/CCLM.2010.012

Cha KH, Sim YB, Chae H, Park HI, Kim M, Kim Y (2014) The analytical performance evaluation of Freelite Human Kappa Free and Human Lambda Free on the SPAPLUS immunoturbidimetric analyzer. J Clin Lab Anal 28:229-236. doi:10.1002/jcla.21671

Clinical and Laboratory Standards Institute (2003) Evaluation of the linearity of quantitative measurement procedures: a statistical approach; approved guideline. CLSI document EP06-A, CLSI, Wayne, PA

Clinical and Laboratory Standards Institute (2004) Evaluation of precision performance of quantitative measurement methods. CLSI document EP05-A2, CLSI, Wayne, PA

Dimopoulos M, Kyle R, Fermand JP, Rajkumar SV, San Miguel J, Chanan-Khan A, Ludwig H, Joshua D, Mehta J, Gertz M, Avet-Loiseau H, Beksac M, Anderson KC, Moreau P, Singhal S, Goldschmidt H, Boccadoro M, Kumar S, Giralt S, Munshi NC, Jagannath S (2011) Consensus recommendations for standard investigative workup: report of the International Myeloma Workshop Consensus Panel 3. Blood 117:4701-4705. doi:10.1182/blood2010-10-299529 (blood-2010-10-299529 [pii])

Dispenzieri A, Kyle R, Merlini G, Miguel JS, Ludwig H, Hajek R, Palumbo A, Jagannath S, Blade J, Lonial S, Dimopoulos M, Comenzo R, Einsele H, Barlogie B, Anderson K, Gertz M, Harousseau JL, Attal M, Tosi P, Sonneveld P, Boccadoro M, Morgan G, Richardson P, Sezer O, Mateos MV, Cavo M, Joshua D, Turesson I, Chen W, Shimizu K, Powles R, Rajkumar SV, Durie BG (2009) International Myeloma Working Group guidelines for serum-free light chain analysis in multiple myeloma and related disorders. Leukemia 23:215-224. doi:10.1038/leu.2008.307 (leu2008307 [pii])

Dispenzieri A, Katzmann JA, Kyle RA, Larson DR, Melton LJ 3rd, Colby CL, Therneau TM, Clark R, Kumar SK, Bradwell A, Fonseca R, Jelinek DF, Rajkumar SV (2010) Prevalence and risk of progression of light-chain monoclonal gammopathy of undetermined significance: a retrospective population-based cohort study. Lancet 375:1721-1728. doi:10.1016/ S0140-6736(10)60482-5 (S0140-6736(10)60482-5 [pii])

Freelite $^{\text {TM }}$ Human Kappa Free and Human Lambda free light chains package insert (2001) The Binding Site Group Ltd., Birmhingham, UK

Hansen CT, Munster AM, Nielsen L, Pedersen P, Abildgaard N (2012) Clinical and preclinical validation of the serum free light chain assay: identification of the critical difference for optimized clinical use. Eur J Haematol 89:458-468. doi:10.1111/ejh.12013

Hoedemakers RM, Pruijt JF, Hol S, Teunissen E, Martens H, Stam P, Melsert R, Te Velthuis H (2011) Clinical comparison of new monoclonal antibody-based nephelometric assays for free light chain kappa and lambda to polyclonal antibody-based assays and immunofixation electrophoresis. Clin Chem Lab Med 50:489-495. doi:10.1515/CCLM.2011 (793/j/cclm.2012.50. issue-3/cclm.2011.793/cclm.2011.793.xml [pii])

Katzmann JA, Abraham RS, Dispenzieri A, Lust JA, Kyle RA (2005) Diagnostic performance of quantitative kappa and lambda free light chain assays in clinical practice. Clin Chem 51:878-881. doi:10.1373/ clinchem.2004.046870 (clinchem.2004.046870 [pii])

Kim HS, Shin KS, Song W, Kim HJ, Park MJ (2014) Clinical comparisons of two free light chain assays to immunofixation electrophoresis for detecting monoclonal gammopathy. Biomed Res Int 2014:647238. doi:10.1155/2014/647238

Krasowski MD, Davis SR, Drees D, Morris C, Kulhavy J, Crone C, Bebber T, Clark I, Nelson DL, Teul S, Voss D, Aman D, Fahnle J, Blau JL (2014) Autoverification in a core clinical chemistry laboratory at an academic medical center. J Pathol Inform 5:13. doi:10.4103/2153-3539 (129450JPI-5-13 [pii])

Krasowski MD, Chudzik D, Dolezal A, Steussy B, Gailey MP, Koch B, Kilborn SB, Darbro BW, Rysgaard CD, Klesney-Tait JA (2015) Promoting improved utilization of laboratory testing through changes in an electronic medical record: experience at an academic medical center. BMC Med Inform Decis Mak 15:11. doi:10.1186/s12911-015-0137-710 (1186/s12911-0150137-7 [pii])

Lachmann HJ, Gallimore R, Gillmore JD, Carr-Smith HD, Bradwell AR, Pepys MB, Hawkins PN (2003) Outcome in systemic AL amyloidosis in relation to changes in concentration of circulating free immunoglobulin light chains following chemotherapy. Br J Haematol 122:78-84 (4433 [pii])

McTaggart MP, Lindsay J, Kearney EM (2013) Replacing urine protein electrophoresis with serum free light chain analysis as a first-line test for detecting plasma cell disorders offers increased diagnostic accuracy and potential health benefit to patients. Am J Clin Pathol 140:890-897. doi:10.1309/AJCP25IHYLEWCAHJ (140/6/890 [pii])

Morris KL, Tate JR, Gill D, Kennedy G, Wellwood J, Marlton P, Bird R, Mills AK, Mollee $P$ (2007) Diagnostic and prognostic utility of the serum free light chain assay in patients with AL amyloidosis. Intern Med J 37:456-463. doi:10.1111/j.1445-5994.2007.01368.x (IMJ1368 [pii])

Nelson LS, Davis SR, Humble RM, Kulhavy J, Aman DR, Krasowski MD (2015) Impact of add-on laboratory testing at an academic medical center: a 5 year retrospective study. BMC Clin Pathol 15:11. doi:10.1186/ s12907-015-0011-711

Pretorius CJ, Klingberg S, Tate J, Wilgen U, Ungerer JP (2012) Evaluation of the $\mathrm{N}$ Latex FLC free light chain assay on the Siemens BN analyser: precision, agreement, linearity and variation between reagent lots. Ann Clin Biochem 49:450-455. doi:10.1258/acb.2012.011264

Snozek CL, Katzmann JA, Kyle RA, Dispenzieri A, Larson DR, Therneau TM, Melton L 3rd, Kumar S, Greipp PR, Clark RJ, Rajkumar SV (2008) Prognostic value of the serum free light chain ratio in newly diagnosed myeloma: proposed incorporation into the international staging system. Leukemia 22:1933-1937. doi:10.1038/leu.2008.171

Tate JR, Gill D, Cobcroft R, Hickman PE (2003) Practical considerations for the measurement of free light chains in serum. Clin Chem 49:1252-1257

Tate J, Bazeley S, Sykes S, Mollee P (2009) Quantitative serum free light chain assay-analytical issues. Clin Biochem Rev 30:131-140

te Velthuis H, Knop I, Stam P, van den Broek M, Bos HK, Hol S, Teunissen E, Fischedick KS, Althaus H, Schmidt B, Wagner C, Melsert R (2011) N Latex FLC - new monoclonal high-performance assays for the determination of free light chain kappa and lambda. Clin Chem Lab Med 49:1323-1332. doi:10.1515/CCLM.2011.624

Tosi P, Tomassetti S, Merli A, Polli V (2013) Serum free light-chain assay for the detection and monitoring of multiple myeloma and related conditions. Ther Adv Hematol 4:37-41. doi:10.1177/204062071246686310.1177_204 0620712466863

Vercammen MJ, Broodtaerts L, Meirlaen P, Bossuyt X (2015) Overestimation of free light chain antigen excess rate. Clin Chim Acta 444:297-302. doi:10.1016/j.cca.2015.02.047 